\title{
ON CREEP AND RELAXATION OF COMPOSITE GIRDERS WITH PRECAST PRESTRESSED CONCRETE SLABS
}

\author{
By Eiichi WATANABE*, Keiichi HAYASHI**, Hirofumi TAKENAKA*** \\ and Hiroshi NAKAI****
}

\begin{abstract}
Presented in this paper is a study on the creep and relaxation behavior of the composite girders with the precast prestressed concrete slabs using a simple linear visco-elastic model for the concrete slab and by making use of the Laplace and its numerical inverse transforms in view of the principle of correspondence to the linear elasticity.

The comparison of the analytical results with those of long-term experiments on precast prestressed slabs and composite girders specifically scheduled and conducted by the authors have shown that upon determination of the visco-elastic constants from the prestressed concrete slab tests, the creep and relaxation behavior of the precast prestressed composite girders presented herein can be reasonably well predicted by a simple linear visco-elastic model.

Keywords : composite girders, precast PC slabs, creep and relaxation
\end{abstract}

\section{INTRODUCTION}

A great number of studies have been reported on the composite girders with precast concrete slabs in the last 3 decades. Since the pioneering work by Sattler in $1960^{11}$, the study has been extended by References 2) 4) and an innovative work by Roik ${ }^{\text {5) }}$ on composite steel girders with precast concrete slab using high tension bolts. Furthermore, the use of precast concrete slabs in Japan is reported in References 6) , 7) and this type of construction is becoming universally accepted, particularly in West Germany, Switzerland, France and $\mathrm{USA}^{8)}$. Most of the RC slabs of Japanese highway bridges are still being built by pouring concrete at the sites. However, concrete slabs poured at the sites are quite difficult to meet the prescribed quality requirement, to cut down human labor and the construction period.

A great number of methods have been proposed so far based on mathematically exact approaches. However, in spite of the fact that these exact formulations are derived mathematically precise, they generally result in extremely sophisticated expressions and are based on relatively uncertain hypotheses such as the Young's moduli of concrete, creep coefficient and shrinkage coefficient and generally they need tremendously large amount of computational time and memory storage.

Discussed in this paper is the prediction of the creep behavior of a new type of composite steel girders with precast prestressed concrete slabs constructed with the longitudinal prestress force and possible releasing of such prestress force after the composition ${ }^{9}$.

The results of the slab tests are used to determine the values of the visco-elastic constants of the PC

* Member of JSCE, Ph. D. \& Dr. Eng., Professor, Kyoto University (Yoshida-Honmachi, Sakyo-ku, Kyoto 606)

** Member of JSCE, Graduate Student, Kyoto University (Yoshida-Honmachi, Sakyo-ku, Kyoto 606)

*** Member of JSCE, M. S., Engineer, Harumoto Iron Works, Ltd., (6-20-24 Minami-okajima, Taishou-ku, Osaka 551)

**** Member of JSCE, Dr. Eng., Professor, Osaka City University, (3-3-138 Sugimoto-cho, Sumiyoshi-ku, Osaka 558) 
slabs; based on these values the numerical analysis on the composite girders has been performed for possible combinations of parameters in such a fashion that the direct comparisons between the analysis and the tests are possible.

\section{A BRIEF OUTLINE OF EXPERIMENTS}

\section{(1) Creep tests on precast concrete slabs}

The main purpose herein is to provide the key data for the determination of the basic creep characteristics of the concrete slabs using the test specimens $\mathrm{S}-1, \mathrm{~S}-2$ and $\mathrm{S}-3$, and is concerned with :

(a) Measurement of the creep under constant load,

(b) Measurement of the creep in case of partial releasing of prestress at the stage of 3 days after the initial prestressing,

(c) Measurement of shrinkage strains.

The test specimens are illustrated in Fig. 1. Their dimensions are $80 \mathrm{~cm} \times 100 \mathrm{~cm} \times 7 \mathrm{~cm}$, with the sheaths of diameter $26 \mathrm{~mm}$ arranged with interval of $20 \mathrm{~cm}$ for PC strand of diameter $17 \mathrm{~mm}$. To ensure the uniform reaction of the specimen to the jack load, steel end plates of thickness $22 \mathrm{~mm}$ are embedded at the ends. The 28-day compressive and tensile strength of S-1, S-2 and S-3 varied from 581 to 582 and from 38.6 to 38.7 , respectively, in $\mathrm{kgf} / \mathrm{cm}^{2}$. The magnitude of the introduced prestress force and the stress releasing are given in Table 1.

The initial prestressing force per unit cable is kept to be $11.2 \mathrm{tf}(110 \mathrm{kN})$ through monitoring by load cells of the capacity of $15 \mathrm{tf}$ each. Whenever the prestress force is reduced by more than $5 \%$ of the initial value, the $\mathrm{PC}$-cables are retightened to maintain the initial value.

\section{( 2 ) Creep tests on composite girders}

Fig. 2 shows the dimensions and the instrumentation of the tested composite girders $M G-1$ to $M G-4$. The strain gages are symmetrically placed with respect to the central point of each girder and are wired in the 4 -gage method. The deflection of the girders is measured through the displacement transducers. The 28-day compressive and tensile strength of the specimens varied from 581 to 589 and from 38.0 to 38.4 ,

Table 1 Prestressing and Releasing of Prestress Forces.

\begin{tabular}{|l|c|c|c|c|}
\hline $\begin{array}{l}\text { Specimen } \\
\text { Name }\end{array}$ & $\begin{array}{l}\text { No. of } \\
\text { Specimen }\end{array}$ & $\begin{array}{l}\text { Initial Prestress } \\
\left(\mathrm{kgf} / \mathrm{cm}^{2}\right)\end{array}$ & $\begin{array}{l}\text { Prestress to } \\
\text { Release }\left(\mathrm{kgf} / \mathrm{cm}^{2}\right)\end{array}$ & $\begin{array}{c}\text { Time to Releasing } \\
(\text { day })\end{array}$ \\
\hline S-1 & 2 & 80 & 0 & -- \\
\hline $\mathrm{S}-2$ & 2 & 80 & 40 & 3 \\
\hline S-3 & 2 & 0 & 0 & --- \\
\hline
\end{tabular}

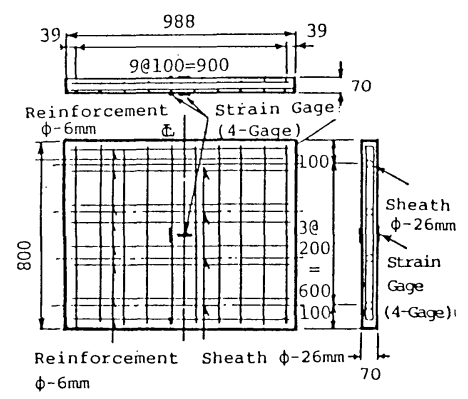

Fig. 1 PC Slabs S-1, S-2 \& S-3.

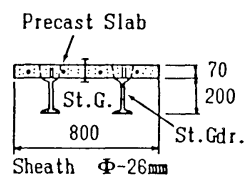

(a) Cross Section

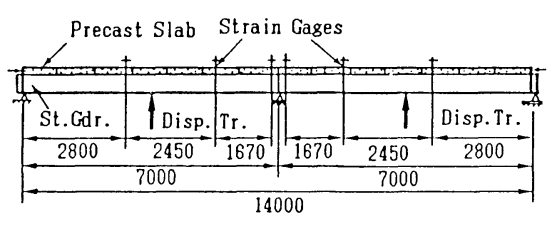

(c) $\mathrm{MG}-4$

Fig. 2 Dimensions and Instrumentation of Tested Composite Girders. 
Table 2 Types and Dimensions of Tested Composite Girders.

\begin{tabular}{|c|c|c|c|c|c|c|c|c|}
\hline \multirow{2}{*}{$\begin{array}{l}\text { Name } \\
\text { of } \\
\text { Spec. }\end{array}$} & \multirow{2}{*}{$\begin{array}{l}\text { Type of } \\
\text { Support }\end{array}$} & \multirow{2}{*}{$\begin{array}{l}\text { Span } \\
\text { Length }(\mathrm{m})\end{array}$} & \multirow{2}{*}{$\begin{array}{l}\text { Prestress } \\
\left(\mathrm{kgf} / \mathrm{cm}^{2}\right)\end{array}$} & \multirow{2}{*}{$\begin{array}{l}\text { Released } \\
\text { Prestress } \\
\left(\mathrm{kgf} / \mathrm{cm}^{2}\right)\end{array}$} & \multirow{2}{*}{$\begin{array}{l}\text { Post-Dead } \\
\text { Load } \\
\text { (tonf/m) }\end{array}$} & \multicolumn{3}{|c|}{ No. Instrumentation } \\
\hline & & & & & & Strain & Disp. & Reactn. \\
\hline MG-1 & S. S. & 5.0 & 80.0 & 0 & 0.5 & 8 & 3 & - \\
\hline MG-2 & S. S. & 5.0 & 80.0 & 0 & 0 & 8 & 3 & - \\
\hline MG-3 & S. S. & 5.0 & 80.0 & 40.0 & 0 & 8 & 3 & - \\
\hline MG-4 & Conti. & $7.0 \times 2=14.0$ & 80.0 & 0 & 0.5 & 24 & 5 & 6 \\
\hline
\end{tabular}

respectively, in $\mathrm{kgf} / \mathrm{cm}^{2}$. Also shown in Table 2 are the magnitude of the initial prestressing force, the amount of the released prestress force and the magnitude of the post-dead load for each of the tested girders, respectively.

\section{COMMENTS ON EXPERIMENTAL RESULTS}

Fig. 3 shows the time-variation of the tensile force of PC cables $\mathrm{S}-1$ and $\mathrm{S}-2$, where the retightening of the $\mathrm{PC}$ cables to maintain the specified tension is clearly seen from the figure. Furthermore, the initial reduction of the tensile force is seen to be about $5 \%$, for the first 10 days; however, on retightening, it is seen to be about $5 \%$ at 150 days after the introduction of the prestress force.

\section{THEORETICAL PREDICTION}

In the following analysis, the precast concrete slab and steel girders are assumed to be linearly visco-elastic and elastic, respectively. According to the Boltzmann's correspondence principle of the linearly visco-elastic body, the equations of equilibrium, compatibility equations and the constitutive equations can be transformed into those of the corresponding linear elastic problems in the Laplace image space. Since the solutions are obtained only at each point of the Laplace image space, the use of the numerical inverse Laplace transform is required to obtain the solutions in the real time domain ${ }^{10) \sim 13)}$.

(1) Linearly visco-elastic model

The creep and relaxation behavior of the precast slab composite girders are quite sophisticated in general. In this study, the precast concrete slabs are considered to be represented by 3-element model as shown in Fig. 4. Then, the constitutive equation, namely, the relationship between the stress, $\sigma(t)$, and the strain, $\varepsilon(t)$, can be shown in the time domain to be given by

$$
\dot{\sigma}(t)+\lambda \sigma(t)=E_{1}\{\dot{\varepsilon}(t)+\mu \varepsilon(t)\}
$$

where $\mu=E_{2} / \eta ; \lambda=\left(E_{1}+E_{2}\right) / \eta ; E_{1}, E_{2}=$ Young's Moduli $\left(\mathrm{kgf} / \mathrm{cm}^{2}\right) ;$ $\eta=$ visco-elastic constant $\left(\mathrm{day} \cdot \mathrm{kgf} / \mathrm{cm}^{2}\right)$

Thus, upon the Laplace transform, the equivalent Young's modulus, $\bar{E}(s)$ in the Laplace image space, $s$ can be obtained as

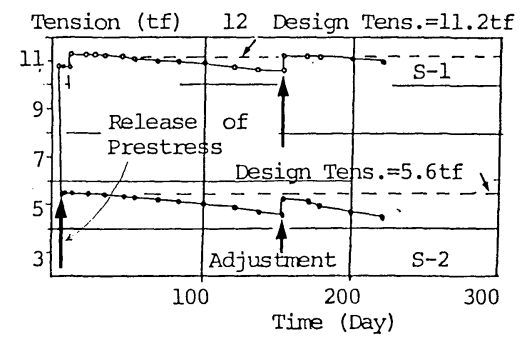

Fig. 3 Time-variation of Tensile Forces of PC Cables. Precast Concrete Slabs S-1 and S-2.

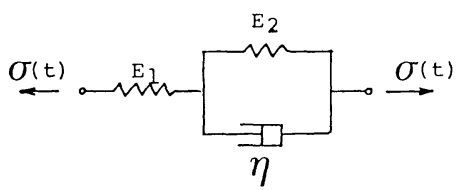

Fig. 4 Linearly Visco-Elastic Model for Concrete Slab. 


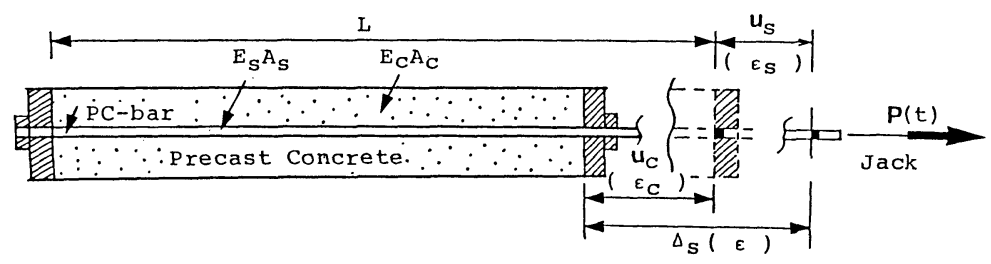

Fig. 5 Creep and Relaxation of Precast Prestressed Concrete Slab.

$\bar{E}(s)=E_{1} \frac{s+\mu}{s+\lambda}$

\section{(2) Precast prestressed concrete plates}

The following visco-elastic analysis is proposed and the constants $E_{1}, E_{2}$, and $\eta$ are to be determined from the experimental results:

(a) First, the prestressing force, $P(t)$, expressed by Eq. (3), is assumed to act on the precast prestressed concrete plate as shown in Fig. 5:

$P(t)=P_{0}\left\{\alpha+(1-\alpha) e^{-\kappa t}\right\}, \quad$ where $P_{0}=P(O)$

(b) The Laplace transforms $\bar{P}(s)$ of $P(t)$ and $\bar{\varepsilon}_{c}(s)$ of the strain of the precast concrete slab, $\varepsilon_{c}$ ( $t$ ) can be shown to be given respectively by:

$\bar{P}(s)=\frac{s+\alpha \varkappa}{s(s+\chi)} P_{o} ; \bar{\varepsilon}_{c}(s)=-\frac{(s+\lambda)(s+\alpha \varkappa)}{E_{1} A_{c}(s+\mu)(s+x)} P_{o} \ldots$

(c) The relationship between the strains of the precast slab and the prestressing cable, $\varepsilon_{c}(t)$ and $\varepsilon_{s}$ $(t)$, respectively, can be obtained in reference to Fig. 10 :

$\left|\varepsilon_{c}(t)\right|+\varepsilon_{s}(t)=\Delta_{s} / L=$ constant

where $L$ and $\Delta_{s}$ refer to the total length and the relative adjustment length of nut at the end of the PC cable. Upon the Laplace transform, the following equation can be obtained :

$s\left|\bar{\varepsilon}_{c}(s)\right|+s \bar{\varepsilon}_{s}(s)=\Delta_{s} / L=$ constant

(d) The substitution of Eq. (6) into Eq. (4) yields the identity:

$\frac{(s+\alpha \chi)\left\{\left(E_{s} A_{s}+E_{c} A_{c}\right) s+\mu E_{c} A_{c}+\lambda E_{s} A_{s}\right\}}{E_{c} A_{c} E_{s} A_{s}(s+x)(s+\mu)} P_{o}=$ constant

Thus, the values of $x$ and $\alpha$ in Eq. (3) can be determined as:

$\varkappa=\frac{\lambda+\mu E_{c} A_{c} /\left(E_{s} A_{s}\right)}{1+E_{c} A_{c} /\left(E_{s} A_{s}\right)} ; \alpha=\mu / \varkappa=\frac{\mu}{\lambda} \frac{1+E_{c} A_{c} /\left(E_{s} A_{s}\right)}{1+\mu E_{c} A_{c} /\left(\lambda E_{s} A_{s}\right)}$

(e) Whereas, the strain $\bar{\varepsilon}_{c}(s)$ of the precast concrete can be obtained by the substitution of Eqs.

(8) into Eq. (4):

$\bar{\varepsilon}_{c}(s)=-\frac{P_{o}(s+\lambda)}{E_{c} A_{c} s(s+x)}$

Upon the inverse Laplace transform, the strain $\varepsilon_{c}(t)$ can be obtained as :

$\varepsilon_{c}(t)=-\frac{P_{o}}{E_{c} A_{c}}\left\{\frac{\lambda}{x}+\left(1-\frac{\lambda}{x}\right) e^{-\kappa_{t}}\right\}$

(3) Precast slab composite girder

Fig. 6 shows the composite girder consisting of its components, namely, the precast slab, steel girder, together with various forces and moments acting on the components and the strains : ${ }^{14) .15)}$

The analysis is proceeded taking into account the composite actions of the components and the elastic deformations of the shear keys in the Laplace image space, $s$. The precast slab undergoes the longitudinal shrinkage due to the creep; however, after the composition, the new stress distribution occurs in the whole cross section.

Let the section immediately after the composition be designated by straight line I- I ; the section at 


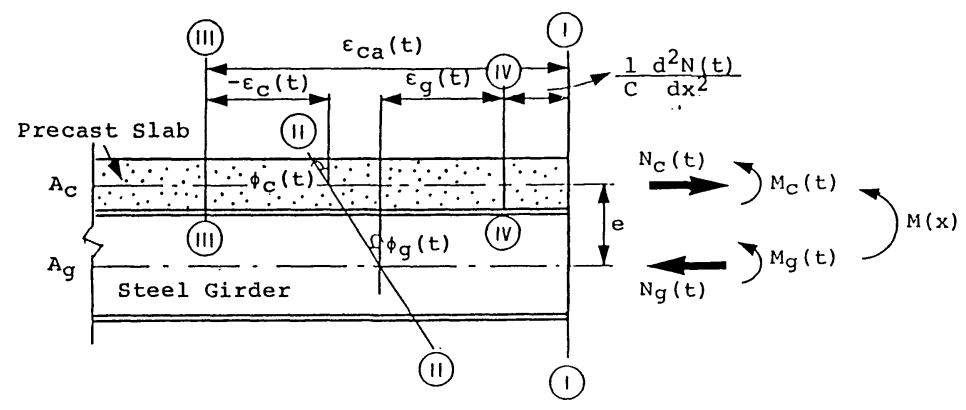

Fig. 6 Strains, Forces and Moments acting on the Composite Girder.

time $t$ after the composition by straight line II - II ; the section provided that the precast slab were not constrained by the steel girder by straight line III-III and the amount of strain due to the elastic deformation of the stud shear connector designated by straight line IV-IV, respectively.

Furthermore, let $N_{c}(t), N_{g}, M_{c}(t), M_{g}(t)$ and $M(x)$ designate the axial tensile force on the slab, axial compressive force on the steel girder, bending moment on the slab, that on the steel girder and the externally applied bending moment, respectively; and let $\varepsilon_{c a}(t), \varepsilon_{c}(t), e \phi_{c}(t)$ and $\varepsilon_{g}(t)$ designate the change of creep strain, $\varepsilon_{c}(t)$ of Eq. (10) subtracted by that corresponding to the time point $t=\tau_{1}$, tensile strain of the precast slab, tensile bending strain evaluated on the basis of the Euler's hypothesis, and the strain of the steel girder, respectively.

Finally, it is to be noted that the strain due to the elastic deformation of the stud is given by $-1 / C \cdot d^{2} N_{c} / d x^{2}$, where $C$ refers to the spring constant of the stud shear connector ${ }^{16)}$.

Thus, considering tensile stress to be positive, the equations of equilibrium of the whole cross section, the following equations can be derived:

$$
\begin{aligned}
& N_{c}(t)=-N_{g}(t) \ldots \ldots \ldots \ldots \ldots \ldots \ldots \ldots \ldots \\
& M_{c}(t)+M_{g}(t)-N_{c}(t) e=M(x)
\end{aligned}
$$

where $e$ designates the distance between the geometrical centers of the precast slab and the steel girder. Besides, the consideration of a single, compatible curvature of the slab and the steel and the compatibility condition of the curvatures and strains, the following equations must hold:

$$
\phi_{c}(t)=\phi_{g}(t)
$$

$\varepsilon_{c a}(t)=\varepsilon_{g}(t)-\varepsilon_{c}(t)-e \phi_{c}(t)-1 / C \cdot d^{2} N_{c}(t) / d x^{2}$

Thus, upon the Laplace transform, the following set of equations can be obtained in the Laplace image space, $s$ :

longitudinal equilibrium: $\quad \bar{N}_{c}(s)=-\bar{N}_{g}(s)$

\section{moment equilibrium :}

compatible curvatures:

$$
\begin{aligned}
& \bar{M}_{c}(s)+\bar{M}_{g}(s)-\bar{N}_{c}(s) e=M(x) / s \\
& \bar{\phi}_{c}(s)=\bar{\phi}_{g}(s) \ldots \ldots \ldots \ldots \ldots \ldots \ldots \ldots \ldots \ldots \ldots \ldots \ldots \ldots \ldots \ldots \ldots
\end{aligned}
$$

$$
\bar{\varepsilon}_{c a}(s)=\bar{\varepsilon}_{g}(s)-\bar{\varepsilon}_{c}(s)-\bar{\phi}_{c}(s) e-(1 / C) d^{2} \bar{N}_{c}(s) / d x^{2}
$$

strain compatibility:

$$
\underline{\phi}_{c}(s)=\bar{M}_{c}(s) /\left(\bar{E}_{c}(s) I_{c}\right) \cdots
$$

curvature of concrete slab: $\bar{\phi}_{c}(s)=\bar{M}_{c}(s) /\left(\bar{E}_{c}(s) I_{c}\right.$

curvature of steel girder: $\bar{\phi}_{g}(s)=\bar{M}_{g}(s) /\left(E_{g} I_{g}\right)$

axial force of concrete slab : $\bar{N}_{c}(s)=\bar{D}_{c}(s) \bar{\varepsilon}_{c}(s)$....

axial force of steel girder: $\bar{N}_{g}(s)=\bar{D}_{g} \bar{\varepsilon}_{g}(s)$.

where

$$
\begin{aligned}
& D_{g}, \bar{D}_{c}(s): \text { Axial rigidity of steel girder and the concrete slab in the Laplace image space, } \\
& \text { respectively, } \\
& E_{g}, \bar{E}_{c}(s): \begin{array}{l}
\text { Young's Modulus of steel girder and the concrete slab in the Laplace image space, } \\
\text { respectively, }
\end{array}
\end{aligned}
$$

$I_{c}, I_{g}$ : Moments of Inertia of concrete slab, and steel girder, respectively, 
$M(x)$ : Bending moment on the composite girder,

$\bar{M}_{c}(s), \bar{M}_{g}(s)$ : Bending moments of concrete slab and steel girder in the Laplace image space, respectively,

$\bar{N}_{c}(s), \bar{N}_{g}(s):$ Axial forces of concrete slab and steel girder in the Laplace image space, respectively,

$\bar{\varepsilon}_{c}(s), \bar{\varepsilon}_{g}(s)$ : Axial strains of concrete slab and steel girder in the Laplace image space, respectively,

$\bar{\varepsilon}_{c a}(s)$ : change of axial strain of concrete slab when the constraint from the steel girder is neglected,

$\bar{\phi}_{c}(s), \bar{\phi}_{g}(s)$ : Curvatures of concrete slab and steel girder in the Laplace image space, respectively.

The solution of the set of simultaneous equations from Eq. (15) to Eq. (22) results in the following equation with respect to $N_{c}(s)$ :

$$
\frac{d^{2} \bar{N}_{c}(s)}{d x^{2}}-\omega^{2} \bar{N}_{c}(s)=-c\left|\bar{\varepsilon}_{c a}(s)\right|+\gamma \frac{M(x)}{s}, \text { where } \omega^{2}=c\left[\frac{e^{2}}{E_{g} I_{g}+\bar{E}_{c}(s) I_{c}}+\frac{1}{D_{g}}+\frac{1}{\bar{D}_{c}(s)}\right] \ldots
$$

and $\gamma=c \frac{e}{E_{g} I_{g}+\bar{E}_{c}(s) I_{c}}$

Since $\bar{\varepsilon}_{c a}(s)$ and $M(x)$ represent a constant and a function of $x$, respectively, $\bar{N}_{c}(s)$ can be obtained approximately by :

$$
\bar{N}_{c}(s)=\frac{c}{\omega^{2}}\left|\bar{\varepsilon}_{c a}(s)\right|-\frac{m \gamma}{\omega^{2}+(\pi / l)^{2}} \sin \frac{\pi x}{l} \text { where } m=-\frac{2}{l} \int_{0}^{l} M(x) \sin \frac{\pi x}{l} d x
$$

Thus, $\bar{\phi}_{c}(x, s)$ can be evaluated by the sum of the constant term, $\bar{\phi}_{c}^{\prime}(s)$, and the variable term, $\bar{\phi}_{c}^{\prime \prime}(x, s)$ :

$$
\bar{\phi}_{c}(x, s)=\bar{\phi}_{c}^{\prime}(s)+\bar{\phi}_{c}^{\prime \prime}(x, s) \quad \text { where } \bar{\phi}_{c}^{\prime}(s)=\frac{e\left|\bar{\varepsilon}_{c a}(s)\right|}{e^{2}+\left[1 / D_{g}+1 / \bar{D}_{c}(s)\right]\left(E_{g} I_{g}+\bar{E}_{c}(s) I_{c}\right)}
$$

and

$$
\bar{\phi}_{c}^{\prime \prime}(x, s)=\frac{\left[(\pi / l)^{2} / C+1 / D_{g}+1 / \bar{D}_{c}(s)\right] M(x)}{\left\{\left[(\pi / l)^{2} / C+1 / D_{g}+1 / \bar{D}_{c}(s)\right]\left(E_{g} I_{g}+\bar{E}_{c}(s) I_{c}\right)+e^{2}\right\} s}
$$

It must be noted that since $\bar{N}_{c}(s)$ and $\bar{\phi}_{c}(s)$ are only obtained as discrete values in the Laplace image space, $s$, their solutions in the real time domain must be obtained by the numerical Laplace transform.

(4) Analysis of continuous composite girders

The analysis can be extended to the case of continuous composite girders by considering its conjugate beam and the elastic load in the Laplace image space taking into account the effect of the indeterminate bending moments at the intermediate supports. The additional equations pertaining to the indeterminate bending moments at the supports can be obtained by considering the corresponding curvatures and satisfying the continuity requirement of the deflectional slope at the indeterminate supports ${ }^{17}$. However, the derivation and the exact form of these equations will be wholly omitted herein.

\section{SUMMARY OF ANALYSIS}

The construction can be classified into three basic stages such as shown in Table 3. Thus, the corresponding relaxation and creep can be given Eq. (24) and Eq. (25), respectively. For the detailed discussions on the non-dimensionalization, the limit theorem of the Laplace transform, and the numerical Laplace transform, the readers are recommended to see References 10) 13).

From the experiments, the non-dimensionalized axial force, $p_{i}=P_{i} / P_{o}$, and the non-dimensionalized axial strain, $q_{i}=\left(t_{i}\right) / \varepsilon_{c_{0}}$, can be obtained for arbitrary time points, $t_{i}(i=1, \cdots, n)$. From Eqs. $(3)$ and (10), the following set of equations can be obtained:

$$
\exp \left(-\varkappa t_{i}\right)=\left(p_{i}-\alpha\right) /(1-\alpha)=\left(q_{i}-\beta\right) /(1-\beta) ; \beta=\lambda / \varkappa \quad(i=1, \cdots, n)
$$

Now, considering the least square scheme, $\frac{\partial I}{\partial \alpha}=0$, on the following quantity, $I$ : 
Table $3 \bar{\varepsilon}_{c a}(s)$ and $M(x)$ for Several Construction Stages of Precast Concrete Slab Composite Girders.

\begin{tabular}{|c|c|c|c|}
\hline & $\begin{array}{c}\text { Step-1 } \\
{\left[\text { composed at } t=\tau_{1}\right]}\end{array}$ & $\begin{array}{l}\text { Step-2 } \\
\text { [release } \theta \% \text { of prestress } \\
\text { force at } t=\tau_{2} \text { ] }\end{array}$ & $\begin{array}{l}\text { Step-3 } \\
\text { [1oaded with post- } \\
\text { dead load q at } t=\tau_{3}\end{array}$ \\
\hline $\bar{\varepsilon}_{\mathrm{ca}}(s)$ & $\begin{array}{l}\bar{\varepsilon}_{\mathrm{ca}}^{-1}(s) \\
=\varepsilon_{\mathrm{o}}\left(1-\frac{\lambda}{K}\right)\left(\frac{1}{s+K}-\frac{e^{-K \tau_{1}}}{s}\right) \\
{\left[\varepsilon_{\mathrm{o}}=\mathrm{P}_{\mathrm{o}} /\left(\mathrm{E}_{\mathrm{C}} \mathrm{A}_{\mathrm{C}}\right)\right]}\end{array}$ & $\begin{array}{l}\bar{\varepsilon}_{\mathrm{ca}}^{2}(s)=\bar{\varepsilon}_{\mathrm{ca}}^{-1}(\mathrm{~s}) \\
-\frac{\theta}{100} \varepsilon_{\mathrm{o}}\left[\frac{\lambda}{\mathrm{sK}}+\left(1-\frac{\lambda}{K}\right) \frac{1}{\mathrm{~s}+K}\right] \mathrm{e}^{-\mathrm{s \tau}_{2}}\end{array}$ & \\
\hline$M(x)$ & & 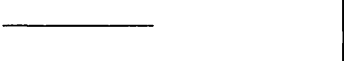 & $\begin{array}{l}M(x)=q x(l-x) / 2 \\
(0 \leqslant x \leqslant l)\end{array}$ \\
\hline
\end{tabular}

$$
I=\frac{1}{2} \sum_{i=1}^{n}\left[(1-\beta)\left(p_{i}-\alpha\right)-(1-\alpha)\left(q_{i}-\beta\right)\right]^{2}
$$

and besides, taking into account the fact that $\rho=E_{2} / E_{1}$ can not be essentially determined without observations in extremely long period, it is temporarily assumed to be constant. Then, the final regression formula can be obtained as follows to determine the value of $\rho$. The final solution can be obtained so that the error, $I$, is minimized with respect to $\alpha$.

$$
\left(a_{11}+2 \zeta a_{12}+\zeta^{2} a_{22}\right) \alpha=b_{1}+\zeta b_{2}
$$

where

$$
a_{11}=\sum_{i=1}^{n}\left(q_{i}-1\right)^{2} ; a_{12}=\sum_{i=1}^{n}\left(1-p_{i}\right)\left(q_{i}-1\right) ; a_{22}=\sum_{i=1}^{n}\left(1-p_{i}\right)^{2} ;
$$

and $b_{1}=\sum_{i=1}^{n}\left(q_{i}-p_{i}\right)\left(q_{i}-1\right) ; b_{2}=\sum_{i=1}^{n}\left(q_{i}-p_{i}\right)\left(1-p_{i}\right) \quad \beta=\frac{\lambda}{\varkappa}=\frac{\lambda}{\mu} \frac{\mu}{\varkappa}=\zeta \alpha ; \zeta=\frac{1+\rho}{\rho}$

Furthermore, shown in Fig. 8 are (a) the time variation of $\bar{\phi}_{c}(x, s)$ in the Laplace image space, $s$, and, (b) the time variation of the central deflection of the composite girder, where the nondimensionalization is performed in terms of the delay time, $T: T=\eta / E_{2}=1 / \mu$, namely,

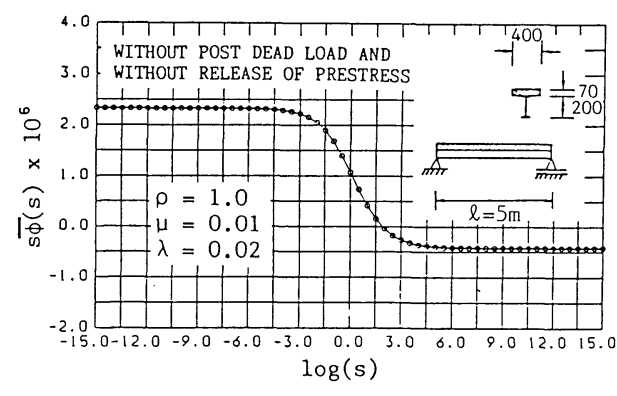

(a) Relationship between $s \bar{\phi}(s)$ and $\bar{s}$. Perfectly Composed, $\zeta=0$.

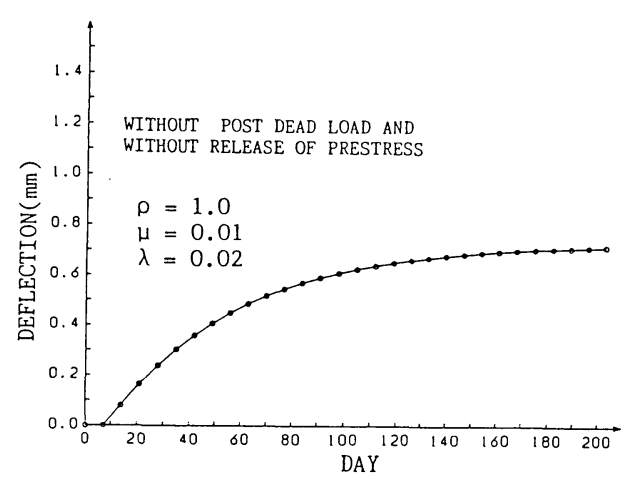

(b) Time Variation of the Central Deflection. Perfectly Composed, $\zeta=0$.

Fig. 8 Curvature and Central Deflection of a Simply Supported Composite Girder without Post-dead Load. $E_{s} / E_{c}=7$.

\section{NUMERICAL DEMONSTRATIONS}

The results of the tests and the corresponding analysis are provided in Figs. 9 12. Based on the regression procedures, Eqs. (27) and (28), the visco-elastic constants such as $\mu, \lambda, \eta, \alpha, \beta, x$ and $\rho$ are determined making use of the time variations of the prestressing force and the strain of the precast 
concrete plate, $\mathrm{S}-1$, the former of which is shown in Fig. 3.

According to Reference 18), the flexibility parameter : $\zeta=\sqrt{C_{o} / C}\left(C_{o}=20 \mathrm{tf} / \mathrm{cm}^{2}\right)$, for the composite slab in the region of the negative bending moment is proposed through experimental study by Nakai et al. to be taken to be 1.9 ; whereas for the region of positive bending moment, it should be taken to be zero. Thus, in this paper, the analysis of the indeterminate composite beams were carried out using for convenience, a single flexibility parameter, $\zeta=1.5$, since the use of this value in the analysis resulted in the best correlation with the experimental values. The more rigorous analysis using seperate value of the flexibility parameter, $\zeta=0$ and $\zeta=1.9$, respectively, for each of the region of the positive bending moment and that of the negative bending moment has been developed by the authors; however, the derivation of the equations must be revised and thus, it will not be mentioned herein.

Shown in Fig. 9 and 10, respectively are the central deflection and the surface strain of the simply supported concrete composite girder, loaded by the post dead load, $0.5 \mathrm{tf} / \mathrm{m}$ when the effect of the elastic deformation of the stud shear connectors is neglected, namely, $\zeta=0$.

Also shown in Figs. 11 and 12, respectively are the central deflection and the surface strain of the two-span continuous precast concrete composite girder, loaded by the post-dead load, $0.5 \mathrm{tf} / \mathrm{m}$, and when the flexibility parameter is taken to be 1.5 .

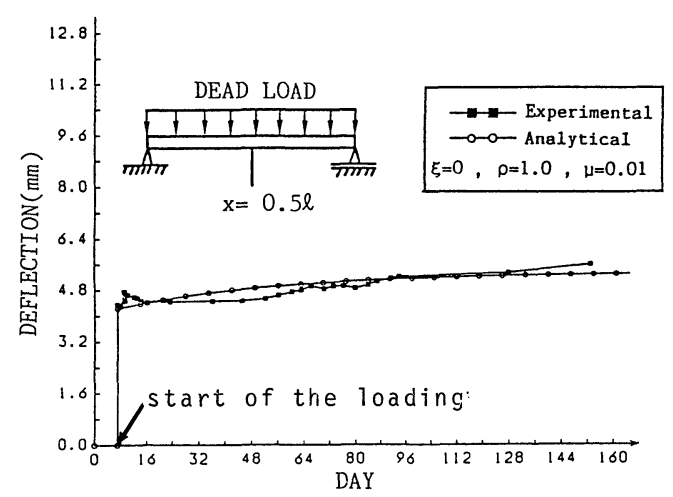

Fig. 9 Time Variation of Central Deflection of a Simply Supported Composite Girder. $E_{s} / E_{\mathrm{c}}=7$. Perfectly Composed : $\zeta=0$. MG-1.

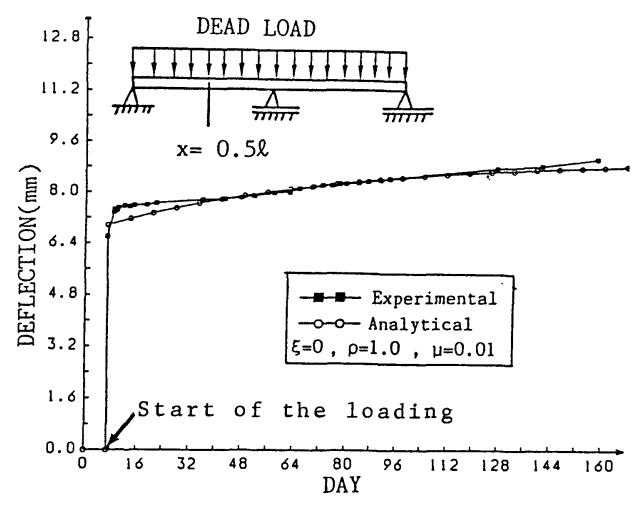

Fig. 11 Time Variation of Central Deflection of a Two-span Continuous Composite Girder. $E_{s} / E_{c}=7$. Test Girder MG-4.

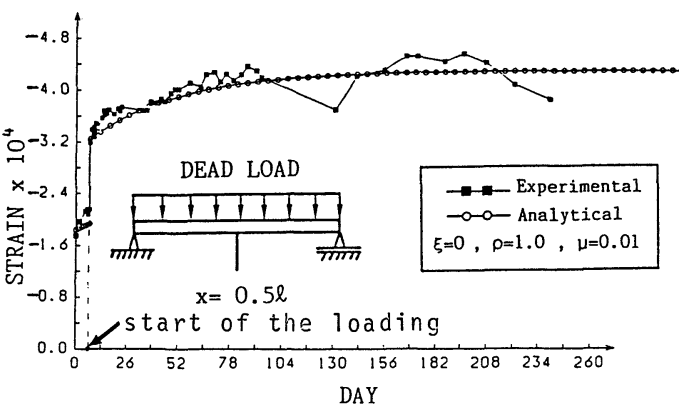

Fig. 10 Time Variation of Surface Strain of Precast Concrete Slab of a Simply Supported Composite Girder. $E_{s} / E_{c}=7$. Girder MG-1.

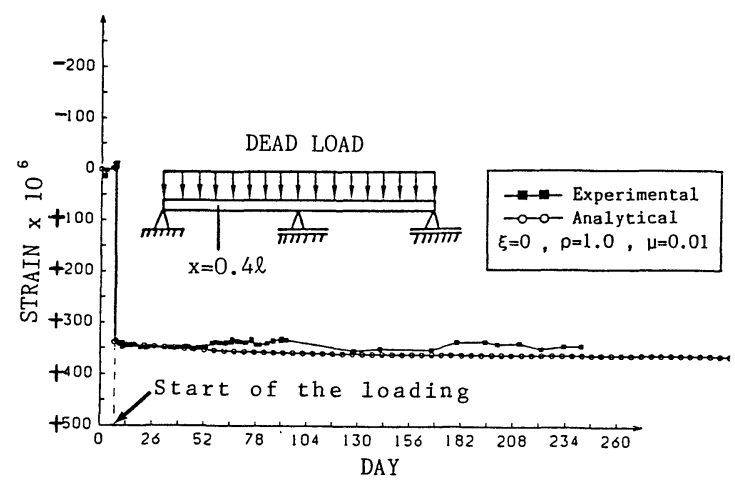

Fig. 12 Time Variation of Surface Strain of the Lower Flange of the steel girder of a Two-span Continuous Composite Girder. $E_{s} / E_{c}=7$. Test Girder MG-4. 


\section{CONCLUDING REMARKS}

This paper is concerned with a series of experiments on the creep and relaxation behavior of precast concrete slab composite girders and a theoretical study on such a behavior by means of a linear visco-elastic model for the concrete slab, the Laplace and its numerical inverse transforms.

The visco-elastic constants of the composite girders are determined based on the results of the precast concrete plates in view of the principle of the least squares. The results of the theoretical analysis turn out to be in good correlation with those of the experiments.

The authors are indebted to the Ministry of Education, Science and Culture of the Japanese Government for a Grant-in-aid for Developmental Scientific Research during the period of 1985 to 1986, and to Shinko Wire Co., Ltd., for every convenience it offered to us during the relaxation testing of PC cables.

\section{REFERENCES}

1) Sattler, K. : Betrachtungen über die Verwendung hochzugfester Schrauben bei Stahlträger-Verbundkonstruktionen, Vorberricht IVBH, s. 330 350, 1960.

2) Beck, H. und Heunisch, M. : Zum Reibungsverbund zwischen Stahl und Beton-fertigteilen bei dübel-losen Verbundkonstruktionen, Der Stahlbau, Heft 2, s. 40 45, 1972.

3) Tachibana, Y., Kondo, K., Iwanaga, Y. and Adachi, Y. : Precast Slab Composite Girder-Its Experimental Study, Journal of JSCE, Vol. 49, pp. 78〜83, 1964.

4) Aschenberg, H. und Reimers, K. : Brücken in dübellosen Verbund-Bewährung beim Bau von Über-führungen über in Betrieb befindlichen Autobahnen, Der Stahlbau, Heft 7, s. 215 221, 1968.

5) Roik, K. und Hanswille, G. : Beitrag zur Ermittlung der Tragfähigkeit von Reib-Abscher-verdubelungen bei Stahlverbund Trägerkonstruktionen, Der Stahlbau, Heft 2, s. 41 48, 1984.

6) Kakuta, Y., Yamadera, T., Sekizawa, S. and Kitajima, A. : Precast Slab Adopted to Metropolitan Expressway Route 5, The Bridge and Foundation Engineering, Vol. 5, pp. 34 42, 1971 (in Japanese).

7) Japan Society of Civil Engineers, Committee on Structural Engineering and Steel-Concrete Composite Structure : Steel and Concrete Composite Structures, Research Report, pp. 43 47, 1983 (in Japanese).

8) Saul, R., Svensson, H., Andra, H. P. und Selchow, H. J. : Die Sunshine-Skyway-Brücke in Florida USA, Bautechnik, s. 230 238, 7/1984.

9) Fujii, M., Nakai, H., Watanabe, E. and Takenaka, H. : Studies on Composite Girder Bridges Using Prestressed Precast Concrete Slabs, US-Japan Seminar, Tokyo, Oct., 1986.

10) Izumi, Y. : A Fundamental Study on Simplification and Economization in Visco-elastic Structural Analysis, Unpublished M. S. Thesis, Kyoto University, 1980 (in Japanese).

11) Yamada, I. : A Fundamental Consideration on the Creep of Cable-stayed Bridges. Unpublished Graduation Thesis, Kyoto University, 1981 (in Japanese).

12) Niwa, Y., Watanabe, E., Matsumura, H. and Yamada, I. : On Time Dependent Deformations of Cables in Cable-stayed Bridges and Their Diagnosis. Symposium on the Soundness and Durability of Existing Bridge Structures and Structural Components, Kansai Branch of JSCE, pp. 149 156, 1982 (in Japanese).

13) Niwa, Y., Nakai, H., Watanabe, E. and Yamada, I. : On Long-term Behavior of Cables in Cable-stayed Bridges, Proc. of JSCE, Structural Eng. /Earthquake Eng., Vol. 3, No. 1, pp. 373 382, 1986.

14) Okada, K., Akashi, T., Kamiyama, H. and Kodama, S. : Material Science for Civil Engineering, 1976 (in Japanese).

15) Ban, S., Okada, K. and Muguruma, H. : Prestressed Concrete, Asakura Shoten, 1960 (in Japanese).

16) Hawranek, A. und Steinhardt, O. : Theorie und Berechnung der Stahlbrücken, Springer-Verlag, 1958.

17) Nakai, H., Watanabe, E., Takenaka, H. and Hayashi, K. : Creep and Relaxation of Precast Concrete Composite Girders, Journal of Structural Engineering, Vol. 33A, 1987 (in Japanese).

18) Yamamoto, R., Nakai, H. and Yamauchi, Y. : Experiments on Load-Carrying Capacity of Continuous Precast Prestressed Slab Composite Girders, Journal of Structural Engineering, Vol. 34A, 1988 (in Japanese).

(Received April 17 1987) 